\title{
MENIMBANG TEORI LATHĀIF UNTUK PERBAIKAN KARAKTER DALAM TAREKAT NAQSYABANDIYAH
}

\section{CONSIDERING LATHĀIF THEORY FOR CHARACTER IMPROVEMENT IN THE NAQSYABANDIYAH ORDER}

\author{
Salahuddin \\ Fakultas Tarbiyah dan Keguruan Universitas Islam Negeri Alauddin Makassar \\ salahuddin@uin-alauddin.ac.id
}

\begin{abstract}
Abstrak
Tulisan ini secara singkat akan menyorot teori dan struktur lathāif dalam Tarekat Naqsyabandi. Tulisan ini dipandang penting karena bisa menjadi tawaran salah satu solusi bagi pembinaan karakter dalam dunia pendidikan kita di Indonesia. Diketahui bahwa tarekat Naqsyabandi merupakan salah satu tarekat yang titik tekannya adalah akhlak, yang dalam tasawuf disebut dengan Tasawuf Amali. Lathāif dalam tarekat ini sebagai media untuk membina dan memperbaiki karakter tersebut. Caranya dengan mengontemplasikan kalimat atau ayat tertentu ke arah/tempat latif itu berada. Meski banyak sufi yang sudah menulis tentang interiosasi batin ini dengan sedikit perbedaan, tapi dari sejumlah tarekat yang ada, hanya di Tarekat Naqsyabandiy yang merumuskan interiosasi batin yang disebut dengan latifah ini dengan secara tegas dan jelas. Latifah inilah yang menjadi sasaran obyek dzikir dalam tarekat ini.
\end{abstract}

Kata Kunci: lathāif, nafs, qalb, khafi, akhfa, ruh, sirr

\begin{abstract}
This paper will briefly highlight the theory and structure of lathaif in the Naqshbandi Order. This paper is considered important because it can offer a solution for character building in our education in Indonesia. It is known that the Naqshbandi Order is one of the orders whose emphasis is on morality, which in Sufism is called Amali Sufism. Lathaif in this order as a medium to foster and improve this character. The trick is to contemplate certain sentences or verses in the direction/place of the lative. Although many Sufis have written about this inner internalization with slight differences, from a number of existing order, only the Naqshbandiy Order has clearly and clearly formulated this inner innerization called latifah. Latifah is the object of dhikr in this order.
\end{abstract}

Keywords: lathāif, nafs, qalb, khafi, akhfa, ruh, sirr

How to Cite: Salahuddin. (2021). Menimbang teori lathāif untuk perbaikan karakter dalam tarekat naqsyabandiyah. Al asma: Journal of Islamic Education, 3(2), 175-182.

\section{PENDAHULUAN}

Membahas manusia dalam kajian tasawuf menjadi hal yang tetap sangat menarik. Dalam pandangan dunia Sufi, manusia terdiri atas dua dimensi: materi kasar (katsif) dan materi lembut (latif) (Adlina, 2012). Dimensi pertama dinyatakan dengan istilah tabiat ( $t a b^{\prime}$ atau tabi'ah) yang bermakna dimensi material atau korporeal. Dimensi kedua dinyatakan dengan berbagai istilah yang mengacu pada batin manusia atau organ-organ 
spiritual. Pada dimensi kedua inilah lathāif (lapisan-lapisan kelembutan) berada (Harvat, 2004).

Cara-cara dan prinsip-prinsip pembagian wujud batin ini berbeda di kalangan kaum Sufi, sementara berbagai istilah teknis yang menandai tingkatan-tingkatan itu juga berbeda. Demikian juga, istilah yang sama dalam berbagai karya Sufi yang berbeda tidak selalu merujuk pada satu dan pengalaman yang sama. Dengan menggabungkan istilahistilah teknis tersebut kaum Sufi menciptakan teori-teori tentang lathaif. Salah satu teori lathāif paling awal diciptakan seorang Sufi Baghdad, Amr ibn Utsman al-Makki (w, 291 H/903[4] M) (Kamada, 1995).

Teorinya tentang interiorisasi terdiri atas empat tataran: raga, kalbu, ruh, dan rahasia, dalam urutan dari yang lebih kasar ke yang lebih lembut. Masing-masing organ mempunyai fakultasnya sendiri seperti salat raga, cinta kalbu, kedekatan ruh, dan kesatuan rahasia. Seorang Sufi pascaklasik, Simnani (w. 736 H/1336 M), mengemukakan skema yang berbeda. la membagi lathaif menjadi lima: jiwa (nafs) kalbu (qalb), rahasia (sirr, ruh (rüh), dan hal-hal yang tersembunyi (khafi) (Cordt, 1977).

Berbagai perbedaan pandangan tentang konsep manusia dalam perspektif tasawuf khususnya dalam menguraikan konsep lathaif menjadi dasar tulisan ini dibuat untuk menguraikan teori dan struktur lathāif dalam Tarekat Naqsyabandi.

\section{METODE PENELITIAN}

Penelitian ini merupakan library research atau penelitian pustaka yang mengkaji tentang teori lathāif untuk perbaikan karakter dalam tarekat naqsyabandiyah. Pembatasan kajian hanya pada bahan-bahan koleksi perpustakaan tanpa memerlukan riset lapangan. Data-data yang didigunakan dalam penelitian ini ialah data data yang berupa karya-karya ilmiah tertulis seperti jurnal, artikel, buku dan karya tertulis lainnya sesuai dengan fokus kajian.

\section{HASIL DAN PEMBAHASAN}

\section{Lathaif dalam Tasawuf}

Kata lathāif berasal dari kata lathif yang berarti lembut. Istilah ini secara umum mengacu pada berbagai esensi lembut dan halus dalam tubuh. Lathaif adalah suatu alat pemahaman spiritual. Ia bukanlah bukanlah sebuah entitas fisikal, melainkan entitas spiritual (Zabidi \& Zabidi, 2017). Dalam tasawuf, istilah ini menunjuk kepada sejenis psikologi, yakni sebuah ilmu tentang kelembutan sebagai buah dari mawas diri yang dilakukan para Sufi dalam usahanya menuju kesempurnaan, yaitu 'pengetahuan' tentang, atau "penyatuan" dengan, Yang Maha Mutlak (Amstrong, 1955).

Adapun istilah-istilah teknis Sufi paling populer mengenai lathāif pada 'diri' manusia yang ada dalam berbagai risalah tasawuf: jiwa (nafs), kalbu (qalb), ruh (rüh), rahasia (sirr), hal-hal yang tersembunyi (khaf), hal-hal yang lebih tersembunyi (akhfa), dan rahasia dari segala rahasia (sirr al-sirr) (Marcia, 1982). Para Sufi juga melihat bahwa lathaif ini paralel dengan realitas alam raya, karena 'diri' manusia dalam pandangan mereka adalah miniatur alam raya. Lapisan fisikal 'diri manusia berada di alam materi; lapis selanjutnya yang lebih tinggi adalah nafs yang setara dengan alam (alam penciptaan); lapis qalb sejajar dengan arsy; lapis ruh setingkat dengan alam malakut (alam 
kerajaan); lapis sirr dan khafi berada pada tingkat alam jabarut (alam kemahaperkasaan); dan lapis akhfa berada pada tingkatan alam lahut (alam ketuhanan). (nasut Kamada, 1995)

Sya ráni (w 973 11/1565 M) menguraikan lathaif ini dalam terma-terma zikir. la menyebutkan tujuh jenis zikir: dzikr al-lisan, dengan lidah; dzikr al-nafs, yang tidak terdengar, tetapi terdiri atas gerak dan rasa; dzikr al-qalb, dengan hati yang merenungkan keindahan dan keagungan Tuhan di dalam dirinya; dzikir al-ruh bila seorang Sufi yang bersemadi mengamati cahaya sifat-sifat; dzikr al-sirr, dalam inti hati, apabila rahasia Ilahi terungkap; dzikr al-khafi zikir rahasia, yang menampakkan cahaya keindahan dari kesatuan sejati, dan dzikr akhfà al-khafi, rahasia segala rahasia, yaitu penglihatan Realitas Kebenaran Mutlak (haqq al-yaqin) (Shulthoni \& Puspitasari, 2012).

Dalam tradisi Naqsyabandi diajarkan bahwa latha'if tersebut harus dijadikan pusat zikir sampai seluruh wujud berubah bentuk. Mir Dard (w. 1785) mengajarkan pelaksanaan teori-teori ini pada akhir abad XVIll. Ia menggambarkan zikir qalb yang bertempat di dada sebelah kiri dan diucapkan dengan cinta dan kerinduan; zikir ruhi, dilakukan di dada sebelah kanan dengan sunyi dan tenang; zikir sirr, dekat dada sebelah kini, dilafalkan dengan penuh keakraban; dan zikir khaf, dekat sudut dada sebelah kiri, bertujuan mengesampingkan dan mematikan diri; dan zikir akhfa, di tengah-tengah dada, tanda peleburan dan penyatuan. Zikir lalu diteruskan ke otak dalam kepasrahan sempurna, dan akhirnya meresapi segenap wujud, badan, dan jiwa. Pada saat itu manusia telah mencapai puncak zikir dan kedamaian yang sempurna, itulah sultan al-adzkar, atau zikir dari segala zikir (Rahmah, 2012). Pada tahap ini, manusia akan dapat mendengar tasbih segala macam makhluk, bebatuan, pepohonan, dinding, pintu, bumi, langit, dan segala sesuatu sampai partikel yang paling kecil sekalipun. Allah berfirman dalam QS. AlIsra'/17: 44, "Tak ada sesuatu pun melainkan bertasbih dan memuji-Nya" (Selim, 2015).

\section{Teori dan Struktur Lathāif dalam Tarekat Naqyabandiyyah}

Di dalam tarekat dikenal setidaknya ada lima titik halus (lathaif) yang padanya diarahkan zikir itu. Kelima titik itu adalah nafs, qalbu, ruh, sir, dan akhfa (Hermansen, 1988). Berikut tinjauan singkat mengenai istilah-istilah kunci tersebut.

Kata nafs dipakai di kalangan para Sufi dengan makna yang beragam. Pertama, ia bermakna 'ego' atau 'diri', yakni realitas (haqiqah) atau esensi (dzát) manusia. Dari sifat komprehensifnya, gagasan tentang nafs kerapkali mencakup kalbu, ruh, dan raga. Hanya saja, dalam banyak hal, nafs adalah 'ego' sebagai tempat dorongan instinktif, yang berasal dari kekuatan yang mendorong seorang Sufi ke arah kejahatan, asal usul kejahatan, dan sumber kecenderungannya untuk mencari kesenangan semata (Anghelescu, 2011). Oleh karena itu, seorang Sufi harus memerangi jiwa (nafs)-nya atau dirinya sendiri, yakni musuhnya yang paling jahat sampai dia bisa menghancurkannya. Kaum Sufi telah mengembangkan pandangan mereka ihwal nafs dengan memahami beberapa tahap nafs, dimulai dari tahap nafs paling rendah sebagai musuh yang menentang kesempurnaan spiritual mereka dan melewati tahap-tahap pertengahan dan berakhir dengan kesempurnaan spiritual yang bersih dari noda atau kejahatan (Metzner, 1988). Dalam banyak kasus, pengklasifikasian beberapa tahap nafs kaum Sufi menggunakan frase-frase Al-Qur'an al-nafs al-ammārah (jiwa yang menyuruh kepada kejahatan), al-nafs allawwamah (jiwa yang mencela), al-nafs al-mutma'innah (jiwa yang tenang), dan al-nafs al- 
mardiyyah (jiwa yang puas). Meski demikian, para Sufi seringkali menunjuk pada nafs sebagai al-nafs al-ammārah bi al-sū' (nafs yang mengajak pada kejahatan) (Ansari, 2006).

Kalbu (qalb) secara etimologis berarti "berbalik" atau "berputar kembali". Dinamai demikian karena sifatnya yang bisa berubah ubah (taqallub).(Hidayat, 2008). Kadang ia cenderung pada kebaikan dan kadang pada kejahatan. Dalam terminologi Sufi, hati menggambarkan substansi spiritual yang terletak antara ruh dan nafs, yaitu suatu substansi yang merupakan tempat terwujudnya sifat-sifat kemanusiaan (Amstrong, 1955). Kalbu adalah 'inti', 'medium antara yang fisikal dan yang spiritual dalam diri manusia. Jika hati mampu melepaskan selubung nafs yang melekat padanya, dia akan berada di bawah pengaruh ruh; itulah yang dikatakan telah menjadi hati dalam makna yang sebenarnya, telah bersih dari segala kotoran keanekaragaman. Hati semacam ini adalah seperti radar yang terus-menerus berputar dan mengamati secara sepintas, tidak pernah terikat pada sesuatu pun di dunia, ia selalu mencari yang suci. Sebaliknya, jika kalbu dikuasai nafs, dia menjadi keruh oleh kotoran keanekaragaman nafs. Karena qalb adalah cermin pengungkapan diri Allah pada kaum Sufi, mereka mesti menyucikan dan menjaganya agar tetap bersih. Kalbu adalah rumah Tuhan dan bagian relung kalbu adalah tempat suci Ilahi. Dengan demikian, secara umum kalbu adalah pusat inti kesadaran manusia (Kamada, 1995).

Ruh (rūḥ) adalah lapisan hati yang menikmati titik pandang cahaya-cahaya Allah, yang pada bagian itu Allah memperlihatkan perwujudan-Nya tanpa tabir penutup. AlGhazali (w 505 H/1111 M) mengklasifikasi ruh menjadi dua: ruh material dalam bentuk uap yang membimbing seluruh raga, dan ruh lembut yang menjadi tempat pengetahuan dan inspirasi (Tritton, 1971). Banyak kaum Sufi berpendapat bahwa ruh adalah esensi manusia, dan bahwa ruh adalah milik Allah, karena QS. Al-Isra/17: 85 menyebutkan bahwa "Ruh adalah urusan Tuhanku (al-rūḥu min amri Rabbi" (Akhyar, 2013). Ruh membentuk diri dalam kehidupan manusia mengambil tempat di hati. Yakni ketika tentara kasih sayang, yang merupakan kekuatan ruh kesatuan mengusir pasukan nafs dari hati. Pada saat itu, jiwa Sufi berhubungan dengan alam kesatuan dan terpisah dari dunia keaneka ragaman. Sekali ruh terlepas dari ikatan-ikatan kekuasaan dan terjauhkan dari gangguarn kekuasaan ilusi dan imajinasi, segala sesuatu di alam al-mulk dan alam malakút akan siap melayani, sehingga seseorang akan dapat menyaksikan tanda-tanda kebesaran Allah di alam jasmani, sementara dalam cermin ruhaninya, dia akan melihat semuanya melalui ruh penyatuan (Haris, 2013). Dalam keadaan ini, jika seseorang melihat melalui jendela perasaan, dia akan melihat segala sesuatu sebagai tanda-tanda kebesaran Allah. Seperti kata para Sufi, "Kemana pun aku memandang, aku melihat Allah." Pada titik ini, cinta telah murni, dan menghilangkan tabir-tabir penutup keindahan namanya. Cinta dan ruh telah herpadu, menjadi satu dan sama, sewaktu kesatuan terjadi. Ke mana pun ruh mencari dirinya, dia akan menemukan cinta (Rohmana, 2015).

Sirr dalam banyak hal terletak sesudah ruh. Menurut para Sufi, sirr adalah organ kontemplasi (musyāhadah), sementara kalbu dan ruh adalah organ-organ pengetahuan Ilahi atau gnosis (ma'rifah) dan cinta (mahabbah). Mereka memandang lathifah sirr lebih halus dan lebih lembut daripada ruh dan asrār (jamak dari sir) ini hanya akan dianugerahkan kepada mereka yang terbebas dari belenggu segala sesuatu selain Allah. Jiwa akan sampai pada tingkat perkembangan sirr, setelah mencapai kesempurnaan pada tingkat perkembangan ruh (Asia, n.d.). Sebagai tingkatan yang lebih tinggi dari ruh, sirr 
adalah akal malaikat yang sakral, terletak di kegaiban Ilahiah yang telah amanah kepada ruh. Penyingkapan sifat-sifat ketuhanan yang mengalir kepada sir dari alam Hakikat Allah dirasakan ruh. Inilah tempat realitas realitas spiritual (ma'na) dari pengetahuan Allah. Objek apa pun yang terlihat oleh sirr itu adalah tersembunyi bagi ruh dan hati, karena objek tersebut adalah pengetahuan Allah yang tak terlihat, yang secara langsung menyentuh sirr tanpa sepengetahuan ruh. Sirr lebih halus daripada ruh, lebih mulia daripada hati. Sirr adalah inti sari seseorang yang dekat dengan Allah, ia tersembunyi, sehingga tidak ada lidah yang dapat menggambarkannya, tidak juga diri individu sendiri mampu memberikan gambaran terhadapnya (Aziz, 2013).

$A k h f a$ atau kesadaran batin terdalam merupakan kesempumaan perkembangan jiwa manusia, suatu maqam yang padanya kaum Sufi melihat Allah melalui Allah dan hanya Allah yang merupakan kesadarannya (Harvat, 2004). Pada tahap perkembangan ini, semua tetesan akan datang bersama-sama, tetapi tidak setetes pun yang dapat ditemukan Dalam lautan inilah al-Hallaj mengutarakan, "Akulah Kebenaran!", dan Abů Yazid berteriak, "Mahasuci Aku!" Di sini tak ada lagi berita dari diri atau kesadaran terhadap diri, semua adalah Allah, dari Allah, dan untuk Allah (Ayouch, 2010). Akhfa atau kesadaran batin terdalam adalah rahasia yang khusus untuk Allah, merupakan pengetahuan realitas realitas yang berlapis-lapis namun menyatu yang terangkum dalam keesaan (ahadiyat) dan pengetahuan dan semua yang terkandung dalam Allah atau milik Allah, sebagaimana dinyatakan Al-Qur'an, "Dan pada sisi Alah-Iah kunci-kunci semua yang gaib, tak ada yang mengetahuinya kecuali Dia sendiri." QS al-An'åm/6: 59). (Budiyanto, 2018).

Lathifah kullu-jasad. Lathifah Rabbaniyyah yang menguasai sekalian jasad. Lathifah ini dihijab oleh sifat lalai dan jahil (Nasution, 1990). Setelah tenaga zikir mengalahkan hijab tersebut akan lahir sifat beramal dan bermakrifat. Apabila lathifah Kullu Jasad sudah terlepas dari sifat kelalaian dan sifat kejahilan, maka sekalian anggota akan tunduk dan ikut serta dalam kegiatan ibadah. Keceriaan ibadah dan zikir akan turut dirasakan oleh sekalian anggota tubuh (Siregar, 2018). Di sini letaknya sifat-sifat jahil "ghaflah" kebendaan dan kelalaian, letaknya diseluruh tubuh mengendarai semua aliran darah kita yang letak titik pusatnya di tepat ditengah-tengah ubun-ubun kepala kita (Anieg, 2017).

\section{Dzikir dan Penyucian Lathaif}

Sebagaimana halnya dengan tubuh jasmani, dalam tubuh rohani pun dapat terjadi gangguan metabolis yang tercermin dari penyakit yang dimilikinya. Tentu saja penyakit yang dimaksud berbeda dengan penyakit secara umum. Misalkan, sifat gemar mencela orang lain tidak dikategorikan sebagai penyakit dalam kajian medis dan psikologi (Hartono, 2007), sedangkan dalam tarekat, sifat tersebut tergolong penyakit yang harus disembuhkan. Secara psiko-spiritual, sifat suka mencela orang adalah penyakit yang dapat mengganggu tubuh rohani dan tubuh jasmani sekaligus (Vandestra, 2017). Oleh karena itu, harus disembuhkan. Akan tetapi, di mana letak sumber penyakit itu? Sifat buruk itu harus disembuhkan dengan cara menghidupkan lathaif-lathaif tersebut (Riswanto, 2015).

Penyucian lathaif merupakan perjuangan spiritual (mujahadah) dalam tarekat atau jalan spiritual. Penyucian setiap lathifah yang terpisah menandai sebuah tahap (langkah maju) dalam perjalanan kembali kepada Allah. Lathaif juga mendefinisikan berbagai kelembutan dan kehalusan dalam diri kaum arif dan pecinta Allah. Di samping zikir, sebagian Sufi melakukan sama' (konser spiritual) sebagai sarana penyingkapan visi mistis 
untuk menyiapkan latha'if ini dalam ekstase spiritual (Nawawi, 2017) Akan tetapi, yang terakhir ini dalam tradisi tarekat Naqsyabandi tidak dijumpai (tidak diperbolehkan) (Julia Day Howell, 2010).

Di atas telah dikemukakan bahwa titik halus (latif) dalam tarekat Naqsyabandi merupakan sasaran dzikir. Tanpa dzikir yang menggempur titik-titik halus tersebut, maka ia akan dikuasai oleh banyak kekuatan jahat yang bersarang di titik tersebut (Nawawi, 2017) Dengan demikian, dzikir yang memang menempati porsi terbesar dalam suatu tarekat, tak terkecuali Tarekat Naqshabandi menjadi senjata ampuh dalam penyucian setiap lathifah tersebut. Dengan mengarahkan setiap dzikir ke arah titik lathifah tersebut, maka titik halus itu akan tunduk dan menjadi tenang karenanya (Zubaidin, 2007). Dalam banyak buku-buku tentang tarekat Naqshabandi, penyucian diri dengan cara ini dibahas.

Satu contoh, dalam meditasi terhadap lathifah nafs dalam Tarekat Naqsyabandi Haqqani Ambil posisi relaks, menghadap ke kakbah, dalam posisi suci. Lalu, mata dipejamkan, telunjuk menempel di ibu jari membentuk huruf 0 , lidah ditempelkan di langit-langit, tarik nafas melalui hidung dan berucap Huuuuuu (wahai Dia). Selesai tarik nafas, ucapkan Allah di dalam kalbu, visualisasi cahaya putih masuk ke perut, keluarkan nafas melalui hidung dan berucap Huuuuu, terus lakukan Hu-Allah-Hu Hu-Allah-Hu (Tarik-simpan keluar) (Julia D Howell, 2002).

Demikian seterusnya untuk lathifah yang lain meski dengan dzikir yang berlainan tergantung kepada sifat jahat yang bersarang di lathifah tersebut (Bariah, 2014).

Demikian secara singkat dipaparkan teori dan struktur lathaif, berikut cara penyuciannya dalam tarekat Naqshabandi di Indonesia.

\section{SIMPULAN}

Meski banyak sufi yang sudah menulis tentang interiosasi batin ini dengan sedikit perbedaan, tapi dari sejumlah tarekat yang ada, hanya di Tarekat Naqsyabandiy yang merumuskan interiosasi batin yang disebut dengan latifah ini dengan secara tegas dan jelas. Latifah inilah yang menjadi sasaran obyek dzikir dalam tarekat ini.

\section{DAFTAR PUSTAKA}

Adlina, A. U. (2012). Mystical experience from religious community of qadiriyah wa naqsyabandiyah dawe kudus. Analisa Journal of Social Science and Religion, 19(1), 37-54.

Akhyar, T. (2013). Esensi sumber daya manusia. Wardah: Jurnal Dakwah dan Kemasyarakatan, 14(1), 35-44.

Amstrong, A. (1955). Sufi terminology, the mystical language of Islam. Malaysia: A.S. Noordeen.

Anghelescu, N. (2011). From lexical to grammatical: Nafs and other identifiers. In In the shadow of Arabic: The centrality of language to Arabic culture (pp. 71-100). BRILL.

Anieg, M. (2017). Merasakan tasawuf. Wahana Akademika: Jurnal Studi Islam dan Sosial, 3(1), 19. https://doi.org/10.21580/wa.v3i1.870

Ansari, Z. A. (2006). Qur anic concepts of human psyche. Adam Publishers.

Asia, S. (n.d.). Naqshbandi sufi order. 
Ayouch, S. (2010). La passion de Husayn Mansûr Al-Hallaj. Topique, (4), 133-147.

Aziz, A. A. (2013). Rekonstruksi metodologi ilmu tasawuf di PTAI. Jurnal Intelegensia, 1(1).

Bariah, K. (2014). Tradisi khataman tarekat naqsyabandiyah pada masyarakat desa Laksamana kecamatan Sabak Auh kabupaten Siak. Universitas Islam Negeri Sultan Syarif Kasim Riau.

Budiyanto, A. (2018). Tentang realitas dari segala sesuatu. Jurnal Filsafat, 28(1), 1-24.

Cordt, H. (1977). Die sitzungen des ala'ad-dawla as-simnani. Juris.

Haris, M. (2013). Spiritualitas Islam dalam trilogi kosmos. Ulumuna, 17(2), 323-346.

Hartono, L. A. (2007). Kesehatan masyarakat stres dan stroke. Yogyakarta: Kanisius.

Harvat, A. (2004). Sufi cosmology and psychology. Sufi Psychology.

Hermansen, M. K. (1988). Shāh Walī Allāh's Theory of the Subtle Spiritual Centers (Lațā̄if): A Sufi Model of Personhood and Self-Transformation. Journal of Near Eastern Studies, 47(1), 1-25.

Hidayat, K. (2008). Psikologi ibadah. Jakarta: Serambi.

Howell, J. D. (2002). Seeking sufism in global city: Indonesia's cosmopolitan muslims and depth spirituality. In Paper to be Presented at Symposium, "Islam in Southeast Asia and China: Regional Faithlines ad Faultlines in Global Ummah (Vol. 28).

Howell, J. D. (2010). Sufism in the modern world. Focus On'essay for the Oxford Islamic Studies On-Line (OISO) Digital Resource.

Kamada, S. (1995). Telaah atas istilah "Sirr" dalam teori-teori lathaif shufi. Al Hikmah Jurnal Studi-Studi Islam, No. 14, Vol. VI.

Marcia, K. (1982). Shah wali Allah of Delhi's arrangement of the subtle spiritual centres (Lathaif). Studies in Islam, 19, 137.

Metzner, R. (1988). On getting to know one's inner enemy: Transformational perspectives on the conflict of good and evil. Human Survival and Consciousness Evolution, 36.

Nasution, H. (1990). Thoriqot qodiriyyah naqsabandiyyah. Institut Islam Lathifah Mubarokkiyah (IAILM).

Nawawi, P. I. (2017). Amalan thariqah an-naqsabandiyah al-khalidiyah dan pengaruhnya terhadap pengembangan nilai-nilai spiritual jamaah di desa ngombak kecamatan Kedungjati kabupaten Grobogan tahun 2017.

Rahmah, N. (2012). Naskah ilmu segala rahasia yang ajaib kontemplasi tarekat naqsyabandiyah dan pembangunan karakter. Jurnal Lektur Keagamaan, 10(1), 75106.

Riswanto, M. C. (2015). Pendidikan akhlak tasawuf pada tarekat qadiriyyah wa naqsyabandiyyah di pondok pesantren suryabuana dusun balak desa Losari kecamatan Pakis kabupaten Magelang tahun 2015. IAIN Salatiga.

Rohmana, J. A. (2015). Sastra sufistik melayu dan sunda di nusantara: Mempertemukan Hamzah Fansuri dan Haji Hasan Mustapa. IBDA: Jurnal Kajian Islam dan Budaya, 13(1), 1-27.

Selim, N. (2015). 9. Sufi body practices and therapeutic politics in Berlin. Somatisierung Des Religiösen: Empirische Studien Zum Rezenten Religiösen Heilungs-Und Therapiemarkt, 237. 
Shulthoni, M., \& Puspitasari, D. (2012). Bisnis kaum santri: Studi tentang kegiatan bisnis komunitas tarekat qadiriyah naqsyabandiyah Pekalongan. Jurnal Penelitian, 8(1).

Siregar, S. (2018). Pola pemahaman keagamaan masyarakat simpang empat pasaman barat (Studi terhadap aliran haqqul yaqin tarekat naqsabandiyah). FITRAH: Jurnal Kajian Ilmu-Ilmu Keislaman, 4(1), 43-66.

Tritton, A. S. (1971). Man, nafs, rūh,'aql. Bulletin of the School of Oriental and African Studies, 34(3), 491-495.

Vandestra, M. (2017). Terapi kesehatan jiwa \& mental dalam Islam. Jakarta: Dragon Promedia.

Zabidi, M. M., \& Zabidi, A. F. M. (2017). Pengukuhan pandangan alam berpaksikan Tauhid: Iktibar dari Al-Lathaif Imam Al-Razi.

Zubaidin, H. M. M. (2007). The power of dzikir: Terapi dzikir untuk kesembuhan dan ketenangan. Klaten: Image Press. 